\title{
Behavioral study of urban watersheds in Bhopal-city of lakes
}

\begin{abstract}
Urbanization have crossed the limits of natural carrying capacity challenging mankind and its development in terms of progress. The most notable changes in the natural system observed are related to the urban and hydrological system where built up areas in urban region have increased from $100,000 \mathrm{~km}^{2}$ in 1994 to $5,000,000 \mathrm{~km}^{2}$ in 2005 . It is assumed that almost $0.5 \%$ of the world surface is occupied by urban areas The aim of the study is to study the behavioural changes in Urban watersheds for recharge and runoff along with increasing Built up areas contributing impervious surfaces over natural ones. Objective is to develop a better understanding of the interactions between surface water flows and water replenishment with changes in land cover characteristics resulting from urbanization at the local, neighbourhood and regional scales. Another objective is to find out relationship between built up and water (surface and sub surface) with empirical, observational and simulation processes for an area with specific climate and physical characteristics. The methodology adopted to study and observe this correlation broadly consist of observation for variations in spatial scale for sub watersheds around 500 or more hectares for urban expansion, changes in land use land cover and hydrological components such as water level in aquifers, wells, runoff and drainages from past to present at temporal scale of about 40years. Conclusion were made on final modelling results with validation and assessment of parameters concluding that runoff is directly proportional to built up and its intensity varies with given roughness land cover, built up and ground water infiltration.
\end{abstract}

Volume 4 Issue 3 - 2020

\author{
Sheetal Sharma \\ Professor, School of Architecture, LNCT University, India
}

Correspondence: Sheetal Sharma, Professor, School of Architecture, LNCT University, Bhopal, India, Emailsheetalsharmaplanner@gmail.com, sheetal.sharma@Inctu.ac.in

Received: May 01, 2020 | Published: May 29, 2020

Keywords: urbanization, land cover land use, runoff-recharge

\section{Introduction}

Urbanization is defined as developing a natural land to an engineered and landscaped one to make it suitable for urban life. World is urbanizing at faster pace with almost $149 \%$ excess built up for present population having 55 to $60 \%$ population residing in urban areas (GRUMP). ${ }^{1}$ The alteration to natural feature reflects in responses of these parameters to previous natural cycle. Almost all processes in a cycle are linked to each other. The processes of evaporation and transpiration (evapotranspiration) are closely linked to the water found in soil moisture ${ }^{2}$ these processes act as driving forces on water transferred in the hydrological cycle. ${ }^{3}$ Evapotranspiration rates depend on many locally specific parameters and variables that are difficult to measure and require demanding analyses in order to calculate an acceptable level of accuracy. Evaporation from surface water bodies such as lakes, rivers, wetlands and reservoirs is also an important component of the hydrological cycle and integral to basin development and regional water management in urban watersheds. Near-surface soil moisture content strongly influences whether precipitation and irrigation waters either run off to surface water bodies or infiltrate into the soil column. Regionally, mapping soil moisture deficit is becoming a widely used technique to link climatologically and hydrological information in agriculture ${ }^{4}$ and to reflect drought conditions. ${ }^{5,6}$

Soil and water conservation is an integral part of watershed management. Although Watershed Management was formerly considered to be nearly synonymous with soil and water conservation, it goes far beyond it today, comprising a variety of further activities that get associated with it in urban areas comprising man - made and natural structures (e.g., building, drainages, roads, parking's etc). Urban watersheds tend difficult to work naturally in modified environments with soil and water being disturbed eventually with activities and land covers. Varying precipitation and population pressure adds to the loss of identification of basic soil and water cycle in watershed. Permissible and exceeding percentage values for built up and resulting runoff on different soil and overlaying land cover roughness as physical planning features affect the water conservation and runoff in colony level to ward level.

Since, presently there is no such definition or limits defined for carrying capacity of natural cycles, the amount of built up to be imposed cannot be restricted, but the impacts of present built up on the soil and resulting recharge and runoff reveal that already Built up has exceeded $65 \%$ of the natural carrying capacity and the permissible limits have been crossed for some watersheds in the study area. 20 to $40 \%$ of the natural working cycle is affected already due to urbanization of watersheds without proper urban planning regulations. With such consideration and observations of water levels in study area a range of built up induction over natural surfaces, the paper attempts to analysis the quantum of impact and proposes physical planning solutions that help in reducing the impacts of urban features on natural cycle. A study of 19 catchments with different soil and land cover is studied with existing laws and resulting impacts on soil and water facts. Methodology consists of analyzing the Built up, modification of natural drainages, water levels for last 40years and application of physical planning laws on the area.

\section{Methodology}

Figure 1. 


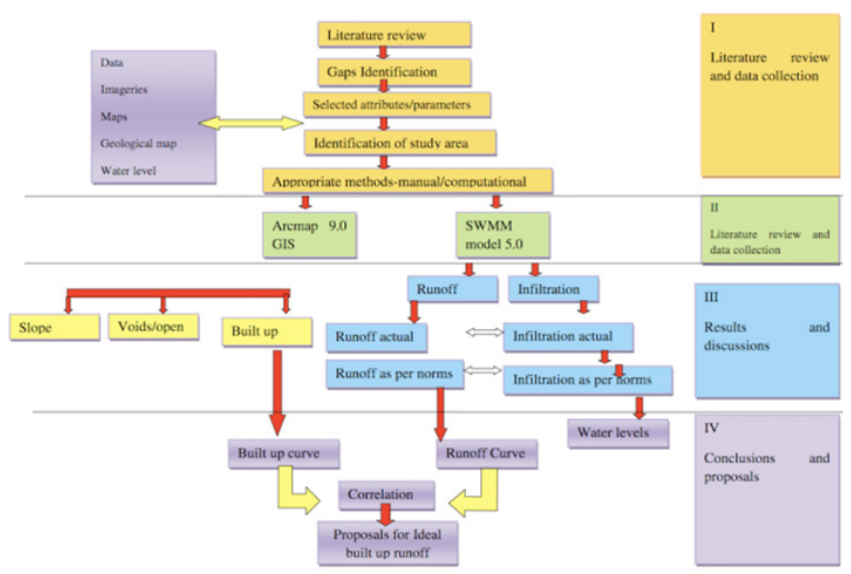

Figure I Methodology.

\section{Study area}

The study area consists of subcatchments as shown in Figure 2, Catchment map of Bhopal city, India having three different types of geology as shown in Map no.3 and appendix A. The purpose of selecting subcatchments with different soils was to correlate the built and resulting runoff with respect to the prevailing soil characteristics and the roughness values for different land covers. Hence for analysis procedure the subcatchments were divided in three groups with respective soils and forth group is considered for impervious soil, which is present in all catchments in some or other form. There were 5 catchments initially, which were again sub divided into small catchments so that details observations could be done for runoff within the catchments and runoff within the whole study area. There are now total $19 \mathrm{catchments}$, having characteristics as per table 20 . These $19 \mathrm{ca}-$ tchments are categorized as per the porosity, water holding capacity, slope and impervious surfaces with open spaces and drainages. The colonies falling in the catchments were identified for further pot and colony level observations for runoff and recharge. These details were transferred into the other software's for modeling purpose.

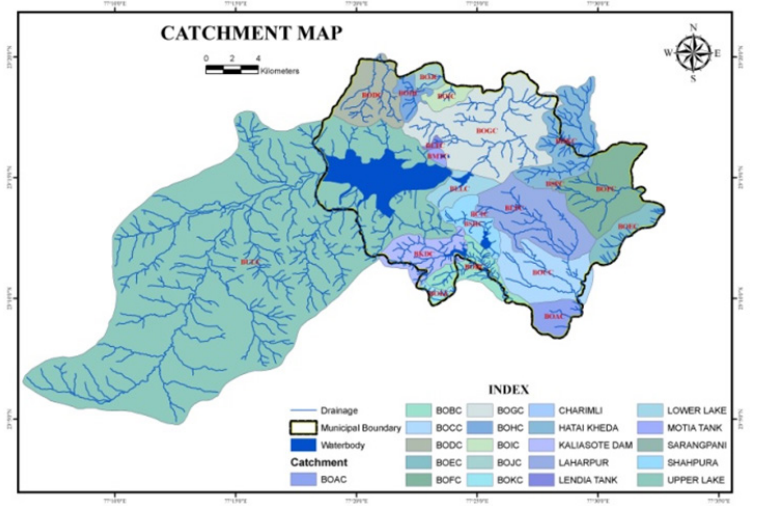

Figure 2 Catchment map of Bhopal City ( Source Centre Ground water Board-M.P).

\section{Analysis and conclusion}

Analysis was carried out by observing changes in built up percentage for the Study area from 1971(toposheet) to 2014 and a chronological table was made for the built and open spaces in the area. GIS software 9.3..$^{7,8}$ was used with temporal imageries obtained from MPCST( Madhya Pradesh Council for Science and Technology). Table no 1 represents the Built up (Buildings, roads, concrete pavements, and all impervious layers on land surface). The percentage of built up area was calculated for each decade.

Figure 4 depicts the changes in Built up in study area urban watersheds from 1971 to 2013. After classification of the land covers, as per Geology and were again separated into two categories i.e. impervious \& pervious. After dividing them in two heads each land cover was assigned by a Manning' $\mathrm{n}$ for the type and category as mentioned above by USGS for SWMM modelling to get Runoff, infiltration, evaporation, Evapotranspiration at given rainfall and soil properties along with contours.

Accordingly a basic model of the study area in Bhopal city was built using the Arc GIS with integration of different layers for different time periods. The precipitation data obtained from the meteorological department and the report of (CWC 1988) WRD 2008 the normal rainfall series and the critical rainfall series were decided. The rainfall data was available in hourly basis as well as monthly basis for monsoon period. Auto cad civil 3D software was used to categories sub catchments on basis of water drop flows and contours of Google surface to facilitate analysis of surface flows.

Thus a whole set of parameters were formed to set a model where simulation for various runoff, peak runoff etc can be observed. The two methods for simulation used were-

i. By keeping precipitation and slope, width constant for respective years and

ii. By changing precipitation on hourly and daily basis to observe long term Runoff changes and short term peak flow changes.

The runoff changes for constant precipitation with decadal built up were analyzed first. The combinations of inter location runoff and the intra location runoff were used to form the correlation equation and the constants $(\mathrm{y}=\mathrm{ax} 2+\mathrm{bx}+\mathrm{c})$ where $\mathrm{y}$ is runoff and $\mathrm{x}$ is built up. The correlation observations for each catchment for each decade was plotted to see the trend line and the resulting equation. To calibrate the hydrologic model the LULC data was prepared in an $8 \mathrm{~m}$ grid. The time series data was made for hourly rainfall event.

Finally the simulation was run for different years as per conditions prevailing for that specified period and the continuity errors as well as flow routing errors were minimized to get accurate results. The obtained report of the rainfall runoff was then observed and compared with varying precipitation and built up observations for viewing results and changes in the parameters. The correlation analysis was performed to obtain a correlation and best fit method was used to get minimum error value. The correlation thus formed was observed for various catchments individually i.e. inter location and then with others with same characteristics over all the study area i.e. intra location.

\section{Basalt}

Increase in Built-up is $42.75 \%$ and simultaneously increase in $\mathrm{Ru}-$ noff $\%$ is $56.63 \%$. Increase in runoff is gradual till 1991-01, but sudden increase is observed in after 1991 from $2.01 \%$ to $45.24 \%$. Though Built up has marginal increase in $0.29 \%$ at 2001 to 2011 , runoff increased $20 \%$. Correlation coefficient is 0.68 and Value of coefficient of determination $\mathrm{R} 2$ is 0.874 .

Increase in built up from $9.44 \%$ to $99.97 \%$ and increase in Runoff from $1.74 \%$ to $71.03 \%$. In this catchment runoff is observed to increase gradually along with Built up time to time. For $43.25 \%$ increase in built up $26.89 \%$ runoff increases showing sudden decadal increase in built up has affected variation in runoff accordingly depicting the sandstone properties. Correlation coefficient is 0.993 and Value of coefficient of determination R2 $=0.970$ 
Increase in Built is observed from $46.78 \%$ to $100 \%$ and runoff from $1.411 \%$ to $73.02 \%$. In this catchment though initial built up was $46.78 \%$ the runoff generated was only $1.4 \%$ materializing the fact that Predevelopment stage had been conserving nature at its best. There is sudden rise in runoff from 1991-2001 from 13.26 to $50.04 \%$, which is the decade year for Bhopal city to get urbanized as master Plan had increased its planning area to double the city. The rate of runoff is found greater than the built up in last 10years. Correlation coefficient is 0.869 and Value of coefficient of determination R2 is 0.912 .

\section{Alluvium}

This catchment has a part with geological characteristics of Alluvium soil and has experienced increase in built up from $2.36 \%$ to $87.18 \%$ and runoff from $0.18 \%$ to $64.77 \%$. The roughness values for this catchment showed a variance for imperious surface of 0.012 roughness to 0.011 and for pervious 0.13 to 0.05 , before and after predevelopment as most of the natural area was made impervious, though some natural parks and open spaces are still restored as natural ones. The recharge potential for this area is too high and has maintained satisfactory water levels in all seasons.

Correlation coefficient is 0.915 and value of coefficient of determination $\mathrm{R} 2=0.906$ (Figure 2).

This catchment has been developed only after 1991 and showed no sign of built up in initial stages having $0.121 \%$ of runoff. After 1991 the urbanization took place steadily and the built up\% reached to 92.75 and resulting runoff to $75.86 \%$, maximum of the study area. This catchment is having the most commercial activities along main roads and open spaces. The runoff didn't show initial rise and has low profile till 1991 then a sudden 54\% increase is observed for 30 increases in Built up. Correlation coefficient is 0.906 and value of coefficient of determination R2 $=0.860$.

This catchment has water body around $50 \%$ of its area and experiences increase in built up from 0.49 to $46.25 \%$ and resulting runoff from 0.0031 to $5.14 \%$. The commercial activities in and around the water body has disturbed the peak flows for this area still maintaining the over all runoff very much less thus helping the recharge potential a lot. Water levels in this area show satisfactory recharge. Correlation coefficient is 0.749 and value of coefficient of determination $\mathrm{R} 2=0.830$.

\section{Sandstone}

The catchment experienced increase in built up from $7.11 \%$ to $82.71 \%$ and Runoff from $7.3 \%$ to $60.17 \%$ in the period. The observations reveal that built up and runoff had been going hand in hand. The flow of runoff from this catchment is towards catchment S6. In the middle period there is a slight fall in runoff from 1991 onwards.

Correlation coefficient is 0.97 and value of coefficient of determination $\mathrm{R} 2=0.817$ (Figure 3).

Increase in built up to $51.87 \%$ from 0 and $35.16 \%$ from $0.15 \%$. Catchment had no urbanization till 1996 and was basically a green belt the land use changed in Master Plan and dramatically honeycombs like colonies flourished in this area with very small plots and colony sizes. Some colonies are observed to have only 8 plots. This honeycomb development haphazardly left no space for proposed city parks or green areas for nurseries as proposed. The ribbon like development interrupts the surface flows from the dam to lake, hence peak flows and flooding are observed for intense rainfall events. Also some conduits show instability for higher rainfall. It has $45 \%$ residential, $47 \%$ natural areas.

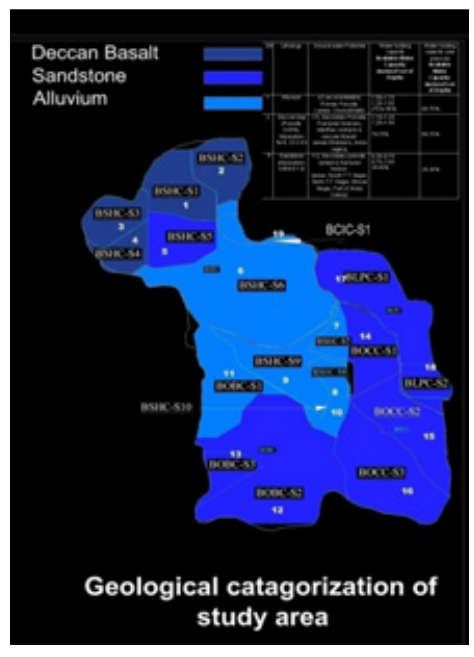

Figure 3 Subcatchments division of study area based on geology. Source: Georesource map of Bhopal District-1998, published by Director general, Geological survey of India).

Correlation coefficient is 0.88 and value of coefficient of determination $\mathrm{R} 2=0.883$ (Figure 4).

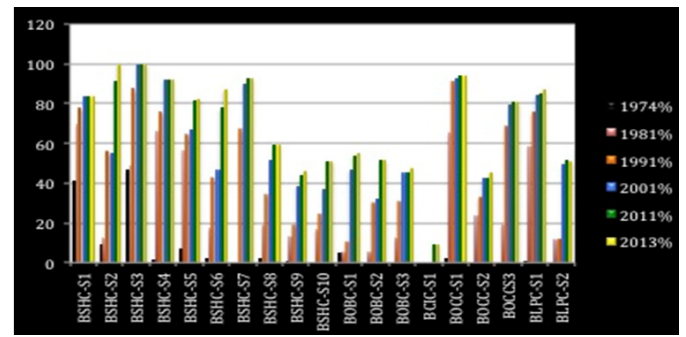

Figure 4 Built up percentage in study area from 197I to 2013.

Basically a slum area out of the city municipal limits having kaccha houses and less R.C.C Construction near the paths of water flows, now turned to developing colonies over the hill tops and rapidly converting hills to flat mounds by excessive excavation of rocks. It also consist a natural park along its natural drains in one part. The increase in built up was observed gradually but being a peri urban area it didn't affected runoff till 1995 and showed a weak relation till then. The runoff increased after 2001.

Correlation coefficient is 0.68 and value of coefficient of determination $\mathrm{R} 2=0.867$.

Observation for runoff pattern in Figure 5 to 13 indicated a particular response by the hydrological system during urbanization. As urban areas increased, the runoff also increased simultaneously. In most of the catchments same response was observed. But some catchments responded in a different way. These had runoff not in linear correlation with built up. Instead the runoff was quite below than the built up as compared to same built up with higher runoff as shown in chart 27, catchments like BSHC-S1, BSHC-S6(high runoff\%) BOBC-S1, BLPC-S1 and BSHC-S3, BSHC-S2 (low runoff\%). The variation in this behaviour was certainly related to some components of both the systems having different response to same situations. To fine out these components it was necessary to analyse individual catchment with its physical characteristics and components reacting to variations in each other. Hence a detail study of catchment, its characteristics like geology, Physiography, drainage, slope, built up, impervious layer, pervious layer and increasing built up pressure was 
studied individually to observe the trend followed by each within the catchment for constant precipitation.

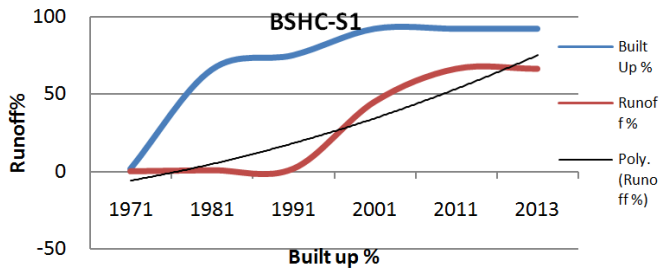

Figure 5 Built up and Runoff variation in BSHC-SI.

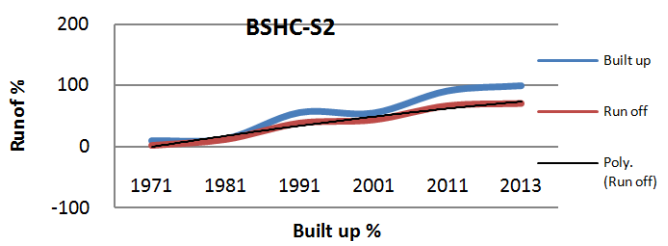

Figure 6 Built up and Runoff variation in BSHC-S2.

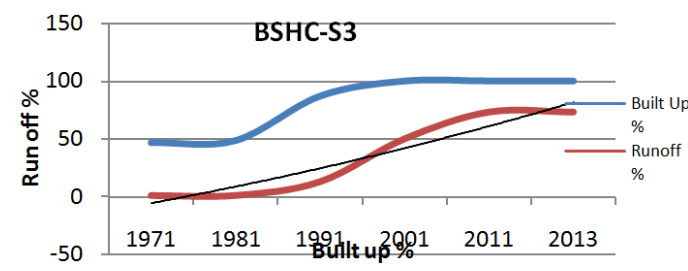

Figure 7 Built up and Runoff variation in BSHC-S3.

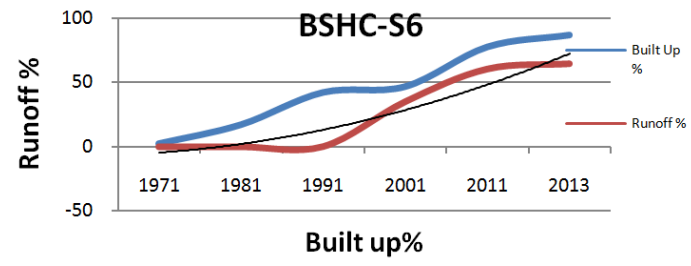

Figure 8 Built up and Runoff variation in BSHC-S6.

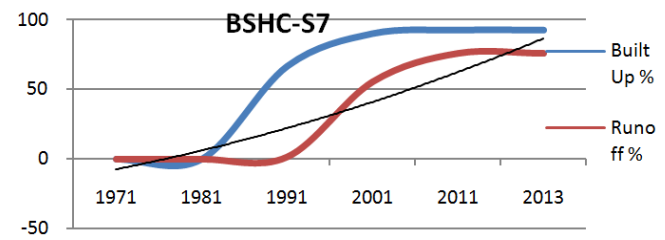

Figure 9 Built up and Runoff variation in BSHC-S7.

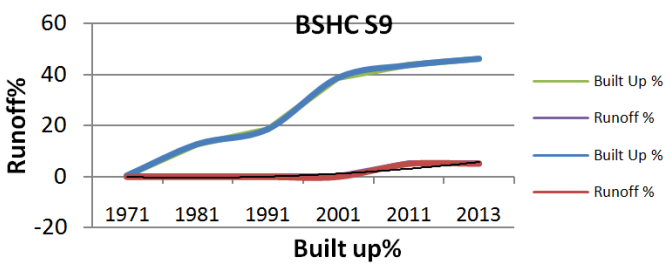

Figure 10 Built up and Runoff variation in BSHC-S9.

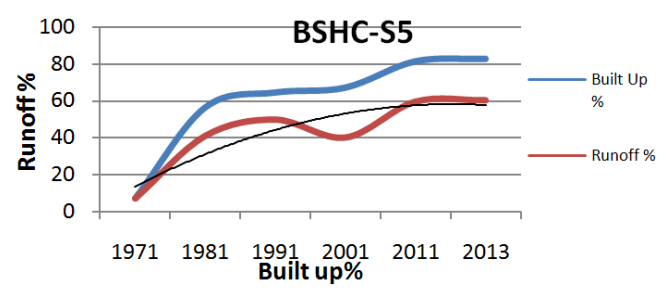

Figure I I Built up and Runoff variation in BSHC-S5.

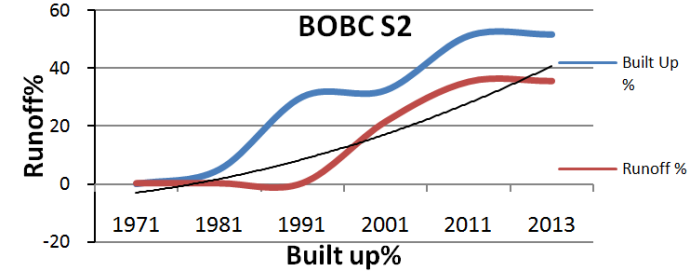

Figure 12 Built up and Runoff variation in BOBC-S2.

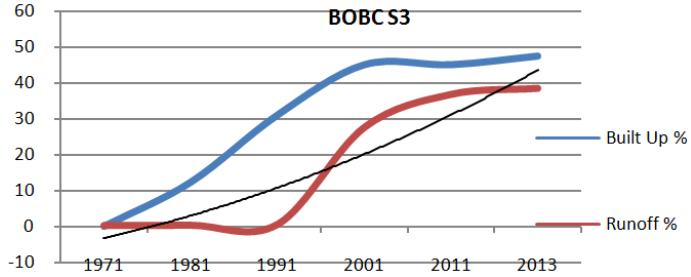

Figure 13 Built up and Runoff variation in BOBC-S3.

Method adopted included same as previous except impervious surfaces and pervious surfaces were given the roughness value as per the existing land covers for the catchments. The simulation was run with constant precipitation for 6 months of monsoon season with built up increase as per decade.

\section{Analysis}

Results obtained from simulation included variations in various components like, evaporation loss, infiltration loss, surface runoff, final surface storage, dry weather flow, wet weather flow etc The most affected components were runoff and infiltration. So, first runoff was selected to continue with the analysis so that a correlation of runoff and built-up can be established. Later infiltration in storage volume in terms of ground water level was also compared. ${ }^{9-11}$

\section{Results and discussion}

Catchments with Basalt soil worked moderately with Built up over it for a range of 65 to $70 \%$ impervious land cover. Sandstone had good response to built up upto 70 to $80 \%$ with supporting land cover as grass and bushes. Infiltration is very good even at high intensity rainfall. Alluvial soil is best to store and recharge rain water if treated with natural soil, dense bushes, connected pervious pathways and small portions of pervious-impervious land covers to make water flow slow getting infiltrated deep in soil. The roughness values, land cover and the geology when compared together with runoff pattern it is clear that alluvial soil when subjected to dense bushes and natural soil cover assures best working of natural cycle. Since urbanization does not support this combination all over, it can be planned at some pockets of urban area having alluvial soil as geological base. Similarly sandstone is good in fast infiltrating the runoff water with the help of grass and medium vegetation land cover. Basalt shows some scope of infiltration if land cover imposed on it is a dense bush or forest. Hence city parks and natural drainages with basalt base should be landscaped with dense bushes. ${ }^{12}$ Land cover with scanty grass and concrete does not support infiltration to a satisfactory level and hence development should be proposed on such pockets with impervious base and least grass or natural cover. These observations help to decide the planning perspective based on geology and land cover. ${ }^{13,14}$

\section{Conclusion}

As per the discussions for carrying capacity of natural water resources, it is clear that presently no such definition or limits could have been defined for carrying capacity of natural cycles, but still an impact on natural working can be seen of the same. Hence considering 
the natural process as basic cycle and proportions of components in natural cycle, the permissible limits can be ascertained with effect to a point where natural processes are getting hampered by the human activities. With such consideration 20 to $40 \%$ above natural cycle, the performance of components etc affected as per other climatic and anthropogenic features. With such consideration and observations of water levels in study area a range of built up induction over natural surfaces was finalized which was found to be in limit of natural processes. ${ }^{12}$

I. Areas with Basalt soil needs open spaces with less vegetation and planned development, having runoff pathways either natural or manmade to allow water to run slowly and directed towards adjoining natural areas. Land cover suitable on these is barren lands with $20 \%$ and more vegetation. Built up induction for smooth natural working is about 40 to $45 \%$ only, in a planned way.

II. Catchments with sandstone soil group favor built up with combination of suitable land covers having cultivated lands and number of pockets of open spaces to allow water infiltrate into soil. The modeling done with open spaces considered as open to ground, around houses and buildings helped to reduce runoff up to $40 \%$ for the study area of this group. Arrangements of gardens, parks, open spaces and parking lots in planned way increases the recharge potential of the area.

III. Alluvial soil has very good water holding capacity but with slow runoff only hence these areas need to intercept the runoff at many places and hence every plot or land should have some percentage of land reserved as recharge pit within it so that immediate runoff starts later and then it has to being intercepted by natural ponding areas or places called as recharge zones (khanti) in India where artificial pond is made to collect extra water.

IV. Almost all catchments supported built up to 45 to $50 \%$ with marginal variations in runoff recharge for water cycle. Hence proper urban planning is needed for inducing more built up on the same area so that working of natural cycle is not hindered and both system work simultaneously. For these many policies are being incorporated such as SUD, water sensitive urban design, Catch water where it falls, Artificial water recharging units etc. apart from these proper land use planning is the most important thing which helps in managing runoff and recharge with natural means and thus making urban planning a more organized and water sensitive based.

\section{Acknowledgments}

None.

\section{Conflicts of interest}

Athors declare that there is no conflict of interest.

\section{Funding}

None.

\section{References}

1. Global Rural-Urban Mapping Project (GRUMP). v1 _ SEDAC.

2. UNFPA, State of world population 2009. Facing a changing world: women, population and climate. Environment. 2009; p. 94.

3. Ipcc. Climate Change 2007: impacts, adaptation and vulnerability: contribution of Working Group II to the fourth assessment report of the Intergovernmental Panel. 2007.

4. United Nations Educational Scientific and Cultural Organization (UNESCO). Water: A Shared Responsibility The United Nations World Water Development Report. Water Resour. 2006;120-156.

5. Loveland JV, Thomas R, Sohl T, et al. Land Cover Trends: Rates, Causes and Consequences of Late-Twentieth Century US. Land Cover Change Land Cover Trends: Rates, Cause, and Consequences of Late-Twentieth Century. 1999;1:44.

6. National I, Conference H. Irish National Hydrology Conference 2008 $2008 ; 85-91$.

7. P SC Chatterjee. Indian National Science Acad. Indian Acad. 1980;1:509514.

8. Sharma KD, Singh S, Singh N, et al. Role of satellite remote sensing for monitoring of surface water resources in an arid environment. Hydrol Sci J. 1989;34(5):531-537.

9. EU. Handbook on Sustainable Urban Drainage Systems. 2013.

10. The national parks act chapter et al. Ecosystems and human well-being: Synthesis. Parks. 2014;5(1954-1960):358-366.

11. Reconstruction P. Land use and physical planning. Nat Hazards; pp. $109-129$

12. Kundzewicz ZW. Freshwater resources and their management. Climate Change 2007 Impacts Adapt Vulnerability Contrib of Working Gr II to Fourth Assess Rep Intergov Panel Clim Chang. 2007;173-210.

13. Coskun HG, Alganci U, Usta G. Analysis of land use change and urbanization in the Kucukcekmece Water basin (Istanbul, Turkey) with temporal satellite data using remote sensing and GIS. Sensors. 2008;8(11):7213-7223.

14. Gironás J, Andrieu H, Roesner L. Alterations to Natural Catchments due to Urbanization, a Morphologic Approach. Novatech 2007. 2007;11991206. 